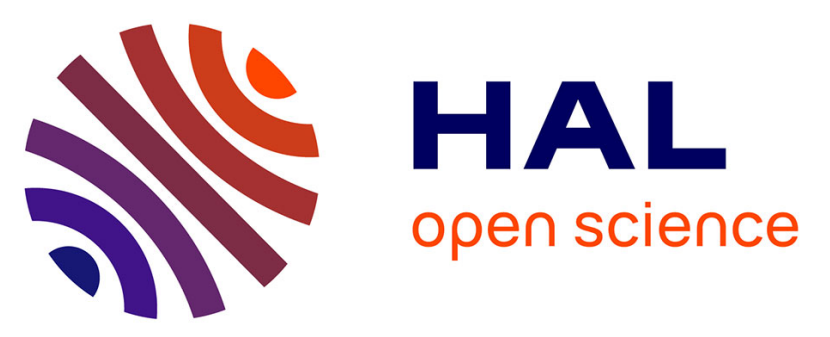

\title{
Communally breeding Bechstein's bats have a stable social system that is independent from the postglacial history and location of the populations
}

Gerald Kerth, Boyan Petrov, Andrej Conti, Danijela Anastasov, Manfred Weishaar, Suren Gazaryan, Julie Jaquiéry, Barbara König, Nicolas Perrin, Nadia Bruyndonckx

\section{To cite this version:}

Gerald Kerth, Boyan Petrov, Andrej Conti, Danijela Anastasov, Manfred Weishaar, et al.. Communally breeding Bechstein's bats have a stable social system that is independent from the postglacial history and location of the populations. Molecular Ecology, 2008, 17 (10), pp.2368-2381. 10.1111/j.1365-294X.2008.03768.x . hal-02659585

\section{HAL Id: hal-02659585 \\ https://hal.inrae.fr/hal-02659585}

Submitted on 30 May 2020

HAL is a multi-disciplinary open access archive for the deposit and dissemination of scientific research documents, whether they are published or not. The documents may come from teaching and research institutions in France or abroad, or from public or private research centers.
L'archive ouverte pluridisciplinaire HAL, est destinée au dépôt et à la diffusion de documents scientifiques de niveau recherche, publiés ou non, émanant des établissements d'enseignement et de recherche français ou étrangers, des laboratoires publics ou privés. 


\title{
Communally breeding Bechstein's bats have a stable social system that is independent from the postglacial history and location of the populations
}

\author{
GERALD KERTH, ${ }^{*}$ BOYAN PETROV „ \\ MANFRED WEISHAAR,II SUREN GAZARYAN, ${ }^{* *}$ JULIE JAQUIÉRY, ${ }^{*}$ BARBARA KÖNIG,† \\ NICOLAS PERRIN* and NADIA BRUYNDONCKX* \\ *Department of Ecology and Evolution, University of Lausanne, Biophore, CH-1015 Lausanne, Switzerland, +Zoologisches Institut, \\ Universität Zürich, Winterthurerstrasse 190, CH-8057 Zürich, Switzerland, †National Museum of Natural History, Blvd Tsar \\ Osvoboditel 1, BG-1000 Sofia, Bulgaria, §Department of Biology and Ecology, Faculty of Sciences, University of Novi Sad, Trg Dositeja \\ Obradovia 3, 21000 Novi Sad, Serbia, IIIm Hainbruch 3, D-54317 Gusterath, Germany, **Laboratory of Biodiversity, Institute of \\ Ecology of Mountain Territories, Kabardino-Balkarian Scientific Centre of RAS, 360000 Nalchik, Russia
}

\begin{abstract}
Investigating macro-geographical genetic structures of animal populations is crucial to reconstruct population histories and to identify significant units for conservation. This approach may also provide information about the intraspecific flexibility of social systems. We investigated the history and current structure of a large number of populations in the communally breeding Bechstein's bat (Myotis bechsteinii). Our aim was to understand which factors shape the species' social system over a large ecological and geographical range. Using sequence data from one coding and one noncoding mitochondrial DNA region, we identified the Balkan Peninsula as the main and probably only glacial refugium of the species in Europe. Sequence data also suggest the presence of a cryptic taxon in the Caucasus and Anatolia. In a second step, we used seven autosomal and two mitochondrial microsatellite loci to compare population structures inside and outside of the Balkan glacial refugium. Central European and Balkan populations both were more strongly differentiated for mitochondrial DNA than for nuclear DNA, had higher genetic diversities and lower levels of relatedness at swarming (mating) sites than in maternity (breeding) colonies, and showed more differentiation between colonies than between swarming sites. All these suggest that populations are shaped by strong female philopatry, male dispersal, and outbreeding throughout their European range. We conclude that Bechstein's bats have a stable social system that is independent from the postglacial history and location of the populations. Our findings have implications for the understanding of the benefits of sociality in female Bechstein's bats and for the conservation of this endangered species.
\end{abstract}

Keywords: glacial refugium, mating system, Myotis bechsteinii, phylogeography, population history, social organization

Received 9 November 2007; revision received 3 March 2008; accepted 13 March 2008

\section{Introduction}

Investigating the genetic characteristics of animal populations over a wide ecological and geographical range is important for at least three reasons. First, information about macro-

Correspondence: Gerald Kerth, Fax: 004121692 4165;

E-mail: gerald.kerth@unil.ch geographical genetic structures allows the reconstruction of recent dispersal (Edwards 1993) and historic colonization events (e.g. postglacial; Hewitt 1996, 1999). Second, information about genetic differences between populations is important for the conservation of endangered species (Palsbøll et al. 2007). Third, genetic data can be used to assess social organizations and mating systems across a species range, which give insights into the intraspecific flexibility of social systems (Lott 1991; Ross \& Keller 1995). 
Despite an increasing number of studies that deal with macro-geographical population structures, there have been no analyses of all three areas in a long-lived mammal.

For small-sized mammals, bats have long lifespans (up to 38 years) and low reproductive rates (normally one to two offspring per year; Wilkinson \& South 2002). Hence, their demography resembles that of much larger mammals for which genetic data on the macro-geographical structure of natural populations are often difficult to obtain. Being colonial, bats are usually easier to sample than big mammals and studies on genetic population structures can be based on much larger sample sizes than in most other wild animals with comparable long generation times. In particular, bats offer the unusual opportunity to obtain representative samples of breeding colonies and mating assemblages throughout the species range. This makes bats exceptionally well suited for a population genetic study of the intraspecific variation in social systems over a large geographical and ecological scale.

Several studies investigated the phylogeography of bats in the Americas, Asia, Australia, and Europe (e.g. Wilkinson \& Fleming 1996; Petit et al. 1999; Worthington Wilmer et al. 1999; Ditchfield 2000; Ruedi \& Castella 2003; Chen et al. 2006; Rossiter et al. 2007). The conclusion of most of these studies is that bats show less phylogeographical structure than similar-sized nonvolant mammals (e.g. Ditchfield et al. 2000). This finding is in agreement with the ability of bats to overcome geographical structures such as rivers and mountains that are often dispersal barriers for rodents, marsupials, and insectivores. At large geographical scales, however, most bats exhibit some phylogeographical structure, with migratory species typically having lower levels of genetic differentiation than nonmigratory species (Wilkinson \& Fleming 1996; Petit et al. 1999; Worthington Wilmer et al. 1999; Russell et al. 2005; Weynand \& van den Busche 2007).

In three European bat species, large-scale sampling of colonies has been used to reconstruct postglacial population histories (Nyctalus noctula, Petit et al. 1999; Myotis myotis, Ruedi \& Castella 2003; Rhinolophus ferrumequinum, Rossiter et al. 2007). The three species differ in their dispersal behaviour but all are capable of dispersing more than $400 \mathrm{~km}$ (Dietz et al. 2007). In M. myotis, Central Europe was primarily re-colonized from Iberia (Ruedi \& Castella 2003). In N. noctula the re-colonization mainly originated from the Balkans (Petit et al. 1999), and in R. ferrumequinum multiple refugia were involved (Rossiter et al. 2007). The only common pattern is that the Balkans and Iberia were the main sources for the postglacial re-colonization, while Italy probably played a minor role, similar to most of the other European animal species (Taberlet et al. 1998; Hewitt 1999). Currently, no comparable large data sets are available for bat species with a maximal dispersal distance of less than $100 \mathrm{~km}$, such as the Bechstein's bat (Dietz et al.
2007). Moreover, no study compared the social system of a bat species inside and outside of an identified refugium in Europe, even though this is important for an assessment of the flexibility of bat social systems.

Bechstein's bats utilize distinct habitats at different stages of their reproductive cycle. During summer, they depend largely on mature deciduous forests, where the females breed communally in tree cavities (Rudolph et al. 2004). Strict female natal philopatry leads to demographically independent breeding colonies that normally comprise about 10-45 maternally related females (Kerth et al. 2000,2002). Males are solitary and disperse from their natal colony (Kerth \& Morf 2004). In autumn, male and female Bechstein's bats swarm in front of caves for mating (Kerth et al. 2003), a phenomenon also known from other European bats (Veith et al. 2004; Rivers et al. 2005). Swarming Bechstein's bats represent a mixture of animals from the local population with members from different colonies meeting at swarming sites that can be $50 \mathrm{~km}$ apart from the breeding colonies (Kerth et al. 2003; Kerth \& Petit 2005).

We used nuclear DNA (nucDNA) and mitochondrial DNA (mtDNA) to resolve the population history and assess the flexibility of the social system of the Bechstein's bat in Europe. Our first goal was to identify glacial refugia of the Bechstein's bat. Glacial refugia are usually expected to harbour higher genetic diversity than areas that have been re-colonized after the ice re-treaded, unless the latter hold an admixture of several source populations (Hewitt 1999; Ruedi \& Castella 2003). This can be determined by constructing mtDNA phylogenies. To reconstruct the population history of the Bechstein's bat, we followed an approach by Petit et al. (1999) and sequenced two mtDNA regions that differ in their mutation rate: the fast evolving $\mathrm{HV} 2$ region (located in the noncoding D-loop) and the more conserved ND1 gene. In a second step, we used seven nuclear and two mitochondrial microsatellite loci (Kerth et al. 2002) to compare the genetic diversity and the population structure inside and outside the area of an inferred glacial refugium. In Central Europe, the social system of the Bechstein's bat is characterized by female philopatry, male dispersal, and outbreeding (Kerth et al. $2002,2003)$. If this social system is conserved over the species' range, we expect higher genetic diversity at swarming sites than in colonies and at least an order of magnitude stronger population differentiation for mtDNA than nucDNA, regardless of whether the populations are located inside or outside of a glacial refugium.

By analysing the population structure of the Bechstein's bat over a large geographical and ecological range, we aim at providing new insights into the factors that shape bat social systems. Bats offer interesting opportunities to study the evolution of sociality (Safi \& Kerth 2007). However, there is a lack of information on the degree of intraspecific 


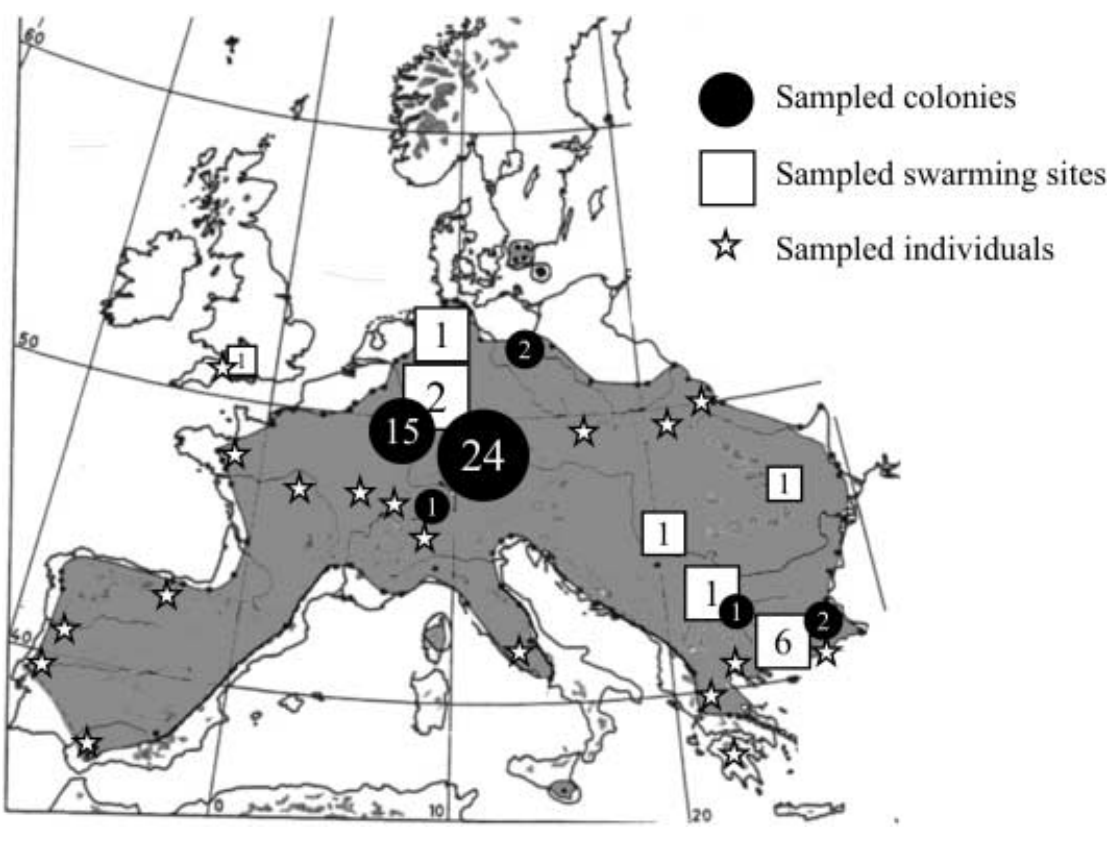

Fig. 1 Map showing the European distribution of Myotis bechsteinii (grey area; modified after Baagøe 2001) and the origin of the analysed samples. The number of sampled colonies and swarming sites at each location are shown in each symbol. Stars indicate the origin of single specimens that have been used for sequencing only. The locations of the samples from the Caucasus and Anatolia are not included in the map. flexibility of bat social systems. This hinders the use of bats in comparative studies because it is unclear how representative data from a single geographical region are. Finally, by identifying management units for conservation (Palsbøll et al. 2007), our study has implications for the protection of the endangered Bechstein's bat.

\section{Materials and methods}

\section{Samples}

Our analyses were based on wing tissue samples $\left(3 \mathrm{~mm}^{2}\right)$ taken from 1508 Bechstein's bats (for sampling methods see Kerth et al. 2000, 2003). This includes 977 adult females (median and range per colony: 14.5; 4-93) from 50 colonies located in Bulgaria (4), Germany (45), and Switzerland (1), as well as 264 males and 136 females from 20 swarming sites (median and range per swarming site: 6.0; 3-103) located in Bulgaria (10), England (1), Germany (6), Romania (1), Serbia (1), and the European part of Turkey (1) (Fig. 1 and Appendix). Bats from 13 colonies and 17 swarming sites were specifically sampled for the current study, whereas samples from 37 colonies and from three swarming sites were available from previous studies (Kerth et al. 2003; Kerth \& Petit 2005). The remaining 131 samples came from bats found across the range in Europe, Anatolia, and the Caucasus (Fig. 1). They were specifically sampled for the current study.

\section{ND1 and HV2 sequence analyses}

After extracting DNA from all wing tissue samples (Kerth et al. 2002), mtDNA was amplified in a subset of the individuals using the polymerase chain reaction (PCR). For the mtDNA sequence analyses, we selected bats from all over the range in Europe (Figs 2 and 3). We restricted the number of sequenced bats per colony to a few individuals (HV2: mean \pm SD: $2.7 \pm 1.7$; ND1: $2.1 \pm 1.0$ ) because most colony members are maternally closely related and thus carry the same mtDNA haplotypes (Kerth et al. 2000). We used the primer pair ER63-AT3 to amplify in 336 bats a segment of the HV2 region and primer pair ER65-ER66 to amplify in 249 bats a segment of the ND1 gene (AT3: 5'-ATAATCGGGTTGGTGAG-3'; for ER63, ER65, ER66 see Petit et al. 1999). For both PCRs, we used $2.5 \mu \mathrm{L}$ 10× Amplimix buffer (Microsynth; including $1.5 \mathrm{~mm} \mathrm{MgCl2}$, and $0.2 \mathrm{~mm}$ dNTP mix), $0.5 \mathrm{U}$ Taq polymerase (Pharmacia), and $0.16 \mu \mathrm{M}$ of each primer. Total reaction volume was $25.0 \mu \mathrm{L}$. A PTC-200 thermocycler (MJ Research) was programmed to perform 35 cycles of $94{ }^{\circ} \mathrm{C} / 30 \mathrm{~s}, 55^{\circ} \mathrm{C} / 45 \mathrm{~s}$ (HV2), respectively, $50^{\circ} \mathrm{C} / 45 \mathrm{~s}$ (ND1), $72{ }^{\circ} \mathrm{C} / 60 \mathrm{~s}$ after an initial $94^{\circ} \mathrm{C} / 4$-min step and followed by $72{ }^{\circ} \mathrm{C} / 20 \mathrm{~min}$. We tested $5 \mu \mathrm{L}$ of the PCR product on a $1.2 \%$ agarose gel $(1 \mathrm{~h}: 4.5 \mathrm{~V} / \mathrm{cm})$ stained with ethidium bromide. PCR products were purified using the ExoSAP-IT (USB Corporation) purification kit $\left(37^{\circ} \mathrm{C} /\right.$ $15 \mathrm{~min}$ and $\left.80^{\circ} \mathrm{C} / 15 \mathrm{~min}\right)$. We used the primer ER63 to sequence $257 \mathrm{bp}$ of HV2 and the primer ER89 (Petit et al. 1999 ) to sequence 482 bp of ND1, using the ABI PRISM BigDye Terminator cycle sequencing ready reaction kit (Applied Biosystems). The resulting PCR products were run on two different capillary sequencers (ABI PRISM 3730 and 310). Data were exported with SEQUENCING ANALYsIS 3.4 (Applied Biosystems) and sequences were aligned and edited with SEQUENCHER 4.1 (Gene Codes Corp). 


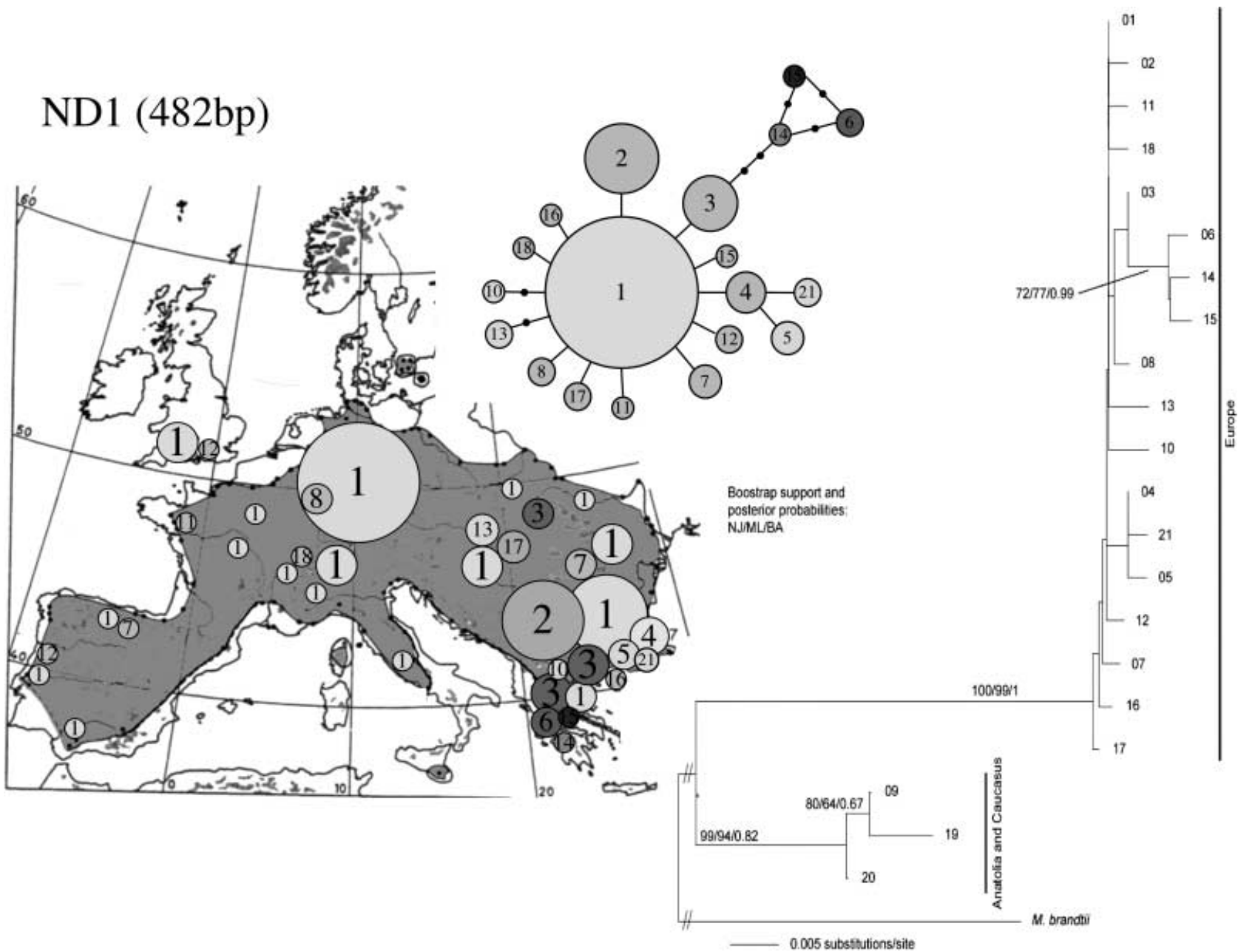

Fig. 2 Origin of 18 ND1 haplotypes of Myotis bechsteinii in Europe, with their MST and NJ tree depicting the phylogenetic relationships between the haplotypes. The NJ tree includes three haplotypes $(9,19,20)$ from the Caucasus and Anatolia as well as Myotis brandtii as an outgroup. Bootstrap indices are given that quantify the support for distance (NJ) and ML analyses (percentage of 1000 and 500 replications, respectively), as well as Bayesian posterior probabilities (BA). The size of the circles in the map and the MST depict the frequency of the respective haplotypes.

\section{Phylogenetic analyses}

To reconstruct phylogenetic relationships between haplotypes (sequences differing by at least one point mutation), we calculated mean pairwise differences and designed minimum-spanning trees (MST) for both HV2 and ND1, using ARLEQUiN 2.0 (Schneider et al. 2000). Deletion and transition weights were set to 1 and we allowed for $5 \%$ of missing data. Phylogenetic relationships between haplotypes were also resolved with three different methods of phylogenetic analyses. Likelihood-ratio tests, implemented in MODELTEST version 3.06 (Posada \& Crandall 1998), were used to determine the best substitution model, which was HKY + G for both data sets $(\gamma=0.3366$ for ND1 and $\gamma=0.0765$ for HV2). A neighbour- joining tree $(\mathrm{NJ})$ was constructed using HKY 85 genetic distances (Hasegawa et al. 1985). The maximum-likelihood analyses (ML) were performed with the software PHYML (Guindon \& Gascuel 2003), which performs fast heuristic searches. Bootstrap support values were obtained with 1000 pseudoreplicates and 10 random replicates of stepwise-addition sequences for NJ using PAUP $^{*}$ version 4.0b10 PPC (Swofford 2002) and with 500 pseudoreplicates for ML using PHYML (Guindon \& Gascuel 2003). Bayesian analyses were conducted using MRBAYES version 3.1.2 (Huelsenbeck et al. 2001), which performs Metropoliscoupled Markov chain Monte Carlo (MCMC) analyses. A Hasegawa-Kishino-Yano (HKY) model was used, with an among-site rate variation following a gamma distribution. The Markov chain was run for 1000000 generations and 


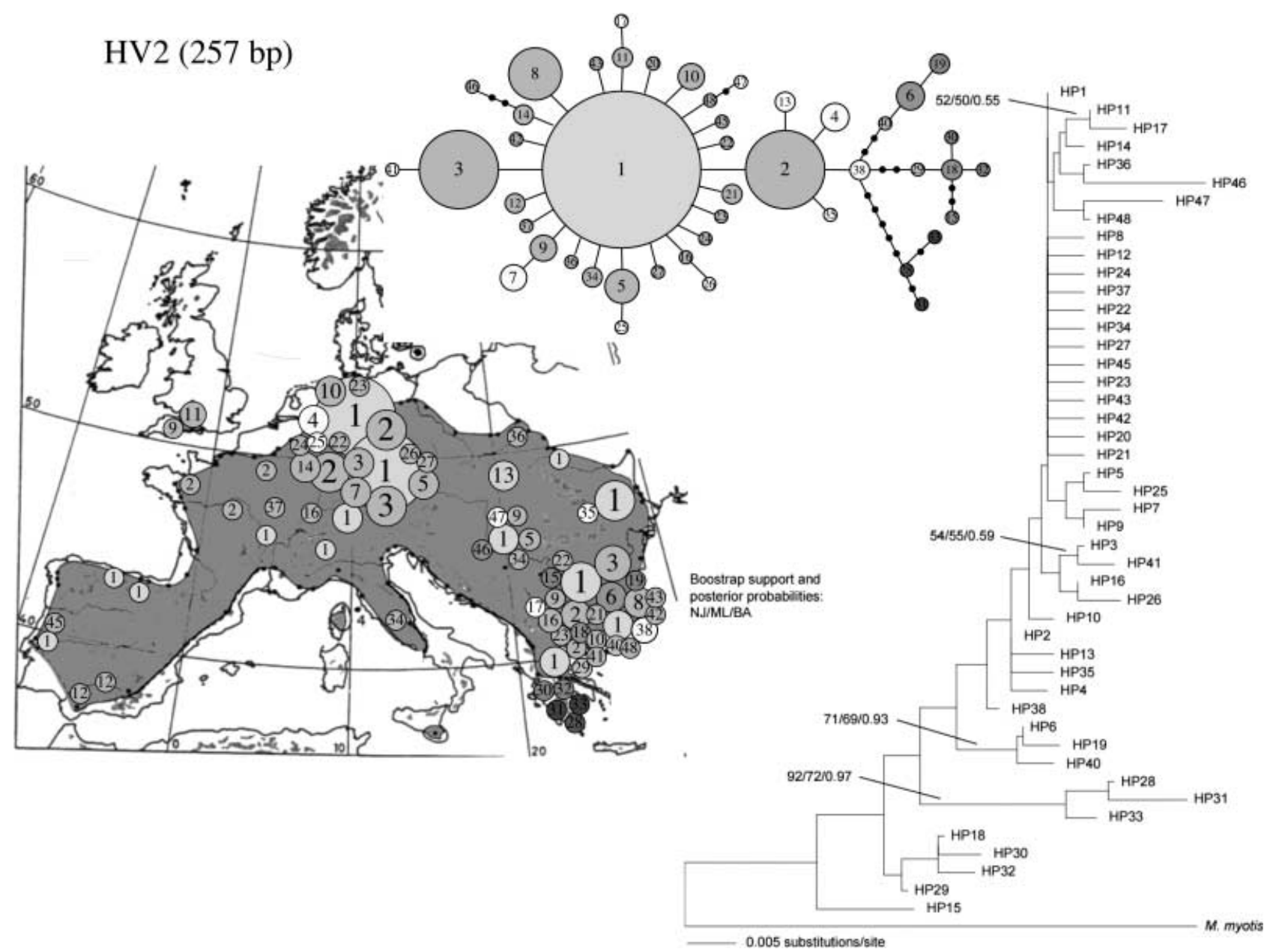

Fig. 3 Origin of $46 \mathrm{HV} 2$ haplotypes of Myotis bechsteinii in Europe, and an MST tree as well as an NJ tree depicting the phylogenetic relationships between the haplotypes. Myotis myotis is used as an outgroup in the NJ tree. Bootstrap indices are given that quantify the support for distance (NJ) and ML analyses (percentage of 1000 and 500 replications, respectively), as well as BA. The size of the circles in the map and the MST depict the frequency of the respective haplotypes.

sampled once every 100 generations; burning-in was set at 100000 generations. All tests were conducted separately on both mtDNA regions (ND1 482 bp, HV2 257 bp), using all codon positions. We did not combine the two mtDNA regions in a single analysis because different numbers of individuals had been sequenced for HV2 and ND1, and as the different mutation rates of HV2 and ND1 provide specific information about population divergence (Petit et al. 1999). The HV2 tree was rooted with sequences of Myotis myotis (GenBank Accession no. AF368772) and the ND1 tree with sequences of Myotis brandtii (GenBank Accession no. AY699868).

To test the hypothesis of recent population growth from low-diversity founder populations within two different regions ('Europe' vs. 'Balkan'), we performed several tests on ND1 and HV2 separately. 'Balkan' included bats from
Bulgaria, the European part of Turkey, and Greece. 'Europe' included bats from Western Europe, Italy, Central Europe, and Eastern Europe north of Bulgaria. We used three methods implemented in ARLEQUIN version 2.0. The first method, Fu's (1997) $F_{\mathrm{S}}$ statistic, tests the probability of observing a random neutral sample with not more alleles than the observed value, given the number of pairwise differences in the sample. This statistic tends to be negative when there is an excess of recent mutations (or rare alleles). The second method, Tajima's (1989) $D$ statistic, tests the null hypothesis that two estimates of the neutral diversity parameter, one derived from the average number of pairwise nucleotide differences and the other based on the number of segregating sites in the sample, are equal. In the third test, pairwise mismatch distributions between individuals were plotted and tested for goodness-of-fit 
to a model of rapid expansion using parametric bootstrapping with 1000 replicates (Schneider \& Excoffier 1999).

We used a bootstrap analysis to test whether the genetic variability of the Iberian samples was significantly lower than of the Balkans samples (which would be expected if the Balkan Peninsula was the main glacial refugium of Myotis bechsteinii). Using the software R (R Development Core Team 2006), we re-sampled the same number of bats (with their associated haplotypes) that had been sequenced for ND1 (respectively HV2) in Iberia, from the total list of sequenced bats from the Balkan. We then computed the average number of mismatches among all pairs of the re-sampled Balkan individuals, and repeated this step 10000 times to generate a null distribution for the number of mismatches. Finally, the diversity of each locus in Iberia was considered to be significantly lower than in the Balkans if its average number of mismatches lay below the fifth percentile of the null distribution.

\section{Genetic diversity within and between breeding colonies and swarming sites}

All 1377 bats sampled in the 50 colonies or at the 20 swarming sites were typed at nine dinucleotide microsatellites (seven autosomal and two mitochondrial loci; for PCR and genotyping conditions see Kerth et al. 2002). We used permutation tests implemented in the software FSTAT 2.9.3 to test for Hardy-Weinberg equilibrium, using $F_{\text {IS }}$ as test statistics, and adjusting for multiple comparisons (Goudet 1995; Goudet et al. 1996).

Since previous analyses of the same loci revealed the suitability of allele identity statistics (Kerth \& Petit 2005), all population structure analyses were based on Weir \& Cockerham's (1984) estimate of $F_{\mathrm{ST}}$ instead of $R_{\mathrm{ST}}$. For the mitochondrial data, alleles at both loci were combined to construct haplotypes. Based on the resulting haplotype frequencies, we calculated the haplotype diversity $(h)$ for mtDNA with fstat. Accordingly, we used the allele frequencies at the seven nucDNA microsatellites to compute the overall gene diversity $\left(H_{\mathrm{S}}\right)$ and allelic richness $\left(A_{\mathrm{R}}\right)$ for nucDNA. We then compared genetic diversities and pairwise $F_{\mathrm{ST}^{-}}$-values for colonies and swarming sites, between populations located inside and outside a glacial refuge, using randomization tests implemented in FSTAT (5000 permutations). Subsequently, we correlated genetic diversities with latitude to test whether latitude had a negative influence on the genetic diversity of the populations. This is expected if the postglacial re-colonization occurred from south to north (Hewitt 1999; Ruedi \& Castella 2003). We give the mean \pm SD for summary statistics, the $P$ value for each test and, whenever available, the proportion of variance explained by the model.

\section{Test for recent bottlenecks}

In historic times, humans reduced and fragmented deciduous forest, which is the main habitat of Bechstein's bats (Rudolph et al. 2004). Deciduous forest was cut all over Europe, however, to a different extent (Mikusinski \& Angelstam 1998). As a result, recent bottlenecks that decrease the local allele diversity might obscure the genetic signal from postglacial colonization. We used the program воттLENECK 1.2.02 to check for local recent bottlenecks (c. 2.0-4.0 $N_{e}$ generations, Luikart et al. 1998; Piry et al. 1999). For populations with at least 10 individuals (minimum sample size required), we tested for bottlenecks by conducting 5000 iterations. As recommended by Piry et al. (1999), we applied a two-phase mutation model composed of $95 \%$ stepwise-mutation model (SMM) and $5 \%$ infinite allele model (IAM), and with $12 \%$ variance of multiple-step mutations. We used the implemented Wilcoxon test to detect whether any of our populations exhibited a significant heterozygote excess, which would be evidence for a recent bottleneck (Cornuet \& Luikart 1996). In addition, we applied the qualitative test for modeshift distortion of allele frequencies using populations with at least 30 samples, as recommended by Luikart et al. (1998).

\section{Results}

\section{Phylogenetic analyses and the location of glacial refugia}

We observed 21 haplotypes defined by 44 base substitutions (40 transitions and 4 transversions) among the 249 bats sequenced for $482 \mathrm{bp}$ of ND1 (GenBank Accession nos EU531436-EU531456). Three haplotypes $(9,19,20)$ only occurred outside Europe (in Anatolia and the Caucasus). These haplotypes differed from the 18 European haplotypes by 25-33 substitutions (5.2-6.8\%). Pairwise differences among the European haplotypes were much lower, ranging from one to six substitutions $(0.2-1.2 \%)$. Bats from the Italian and Iberian peninsulas carried ND1 haplotypes identical or very similar to the Central European haplotypes (Fig. 2). As the three phylogenetic methods gave identical arrangements of the main branches, the relationship between haplotypes is given only for the $\mathrm{NJ}$ analysis. The MST and the phylogenetic trees confirmed the distinctness of the Caucasian and Anatolian haplotypes. Moreover, they consistently showed that three $(6,14,15)$ of the five Greek haplotypes were distinct from the other European haplotypes.

For HV2 (257 bp), we observed 38 polymorphic sites (37 transitions and 1 transversion) that defined 46 haplotypes among the 336 sequenced bats from Europe (GenBank Accession nos EU531390-EU531435). Haplotype divergence ranged from $0.4 \%$ to $4.9 \%$. As for the ND1 gene, the MST had a starlike pattern with one dominant haplotype 
ND1

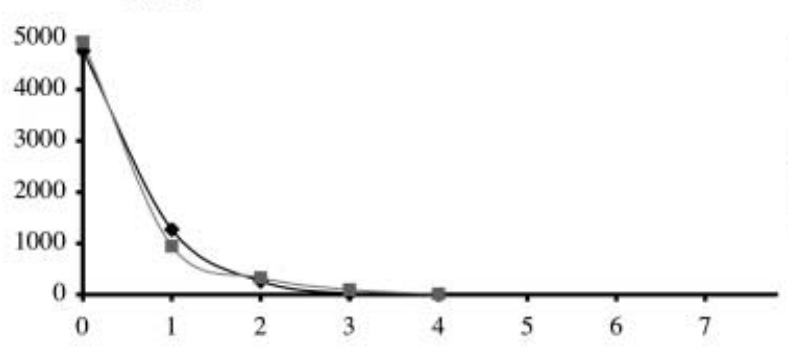

HV2

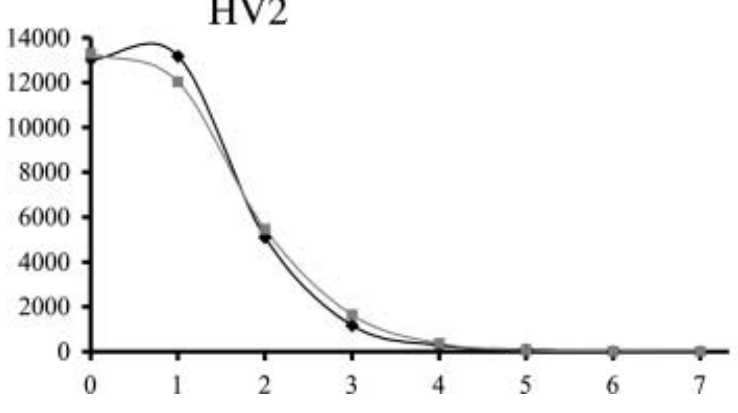

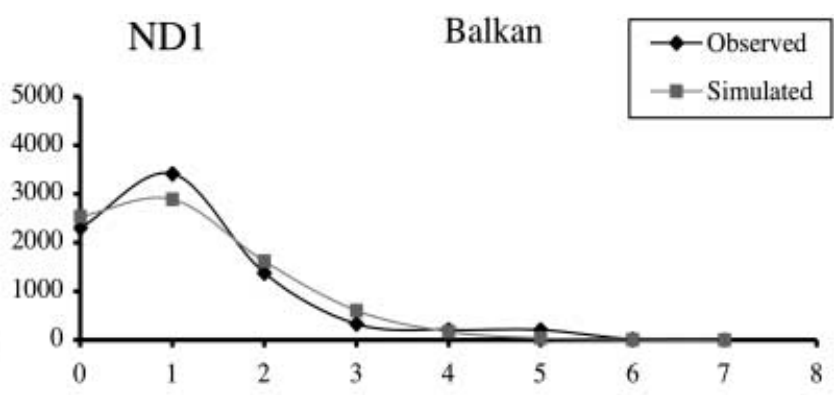

HV2

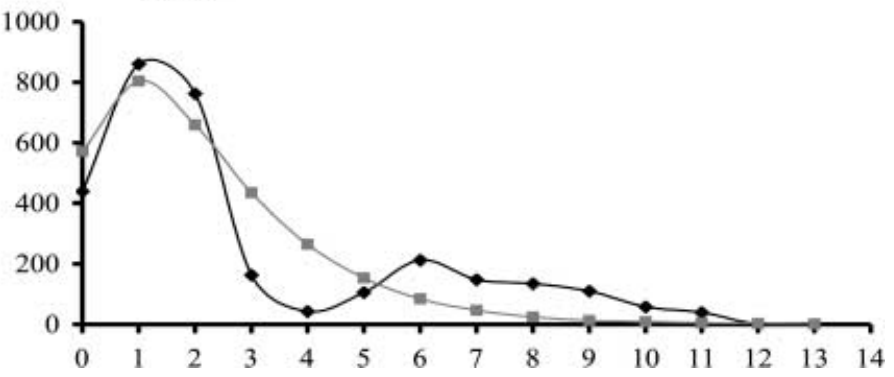

Fig. 4 Observed and expected (simulated) distributions of the number of pairwise differences in Bechstein's bat populations in the 'Balkan' (left graph) and the rest of 'Europe' (right graph). The two upper graphs show the situation for the coding ND1 gene, the two lower graphs the situation for the noncoding HV2 region.

and most other haplotypes being similar to the dominant one, including those from the Italian and Iberian peninsulas. Again, the most distinct haplotypes came from bats caught in the southern Balkan Peninsula (Bulgaria, European part of Turkey, Greece; Fig. 3). Again the three phylogenetic methods resulted in identical arrangements of the main branches, and the relationship between haplotypes is given only for the NJ analysis. Despite a poor bootstrap support (due to the low divergence between haplotypes), the 'cascade-like' pattern of HV2 seems to support the basal position of several Greek and Bulgarian haplotypes $(15,18,19,28-33,38,40)$.

For ND1, we observed a nonsignificant $P$ value for the mismatch distribution test of goodness-of-fit to a scenario of rapid expansion for Europe (Harpending's raggedness index $=0.33, P=0.68)$ and a significant $P$ value for the Balkan (Harpending's raggedness index $=0.11, P=0.006$ ). Moreover, the mode of the mismatch distribution in the Balkan was shifted towards larger pairwise differences compared to the mismatch distribution in Europe (1 vs. 0; Fig. 4). Fu's $F_{\mathrm{S}}$ statistic and Tajima's $D$ were significant for Europe $\left(F_{\mathrm{S}}=-9.57, P<0.0001 ; D=-2.02, P=0.002\right)$, but not significant for the Balkan $\left(F_{\mathrm{S}}=-3.77, P=0.07 ; \mathrm{D}=-1.34\right.$, $P=0.07$; Fig. 4). These results are all in agreement with a scenario of expansion for the European populations and no expansion for the Balkan populations. For HV2, we observed a nonsignificant $P$ value for the mismatch distribution test of goodness-of-fit to a scenario of rapid expansion for Europe (Harpending's raggedness index $=0.08$, $P=0.10$ ) as well as for the Balkan (Harpending's raggedness index $=0.06, P=0.27)$. Again, the mode of the mismatch distribution in the Balkan was shifted towards larger pairwise differences compared to the mismatch distribution in Europe (> 1 vs. $<1$; Fig. 4). Fu's $F_{S}$ statistics was significant for Europe $\left(F_{\mathrm{S}}=-28.98, P<0.0001\right)$, as well as for the Balkan $\left(F_{\mathrm{S}}=-15.27, P<0.0001\right)$ and Tajima's $D$ was significant for Europe $(D=-2.13, P<0.0001)$ but not significant for the Balkan $(D=-1.22, P=0.10$; Fig. 4$)$. The results for HV2 again suggest a scenario of expansion for the European populations, whereas the pattern is less clear for the Balkan populations.

The bootstrap analysis revealed that the average number of mismatches (0.8) among the five bats from Iberia sequenced for ND1 was not significantly smaller than the average number of mismatches (1.2) among the same number of re-sampled bats from the Balkan (the value corresponding to $5 \%$ threshold is 0.4 ). We obtained similar nonsignificant results when using two different subsets of bats from the Balkan as a reference (subset 1: only bats from southern Bulgaria, the European part of Turkey, and Greece; subset 2: only Greek bats; data not shown). For HV2, however, the average number of mismatches (0.9) among the six sequenced Iberian bats was significantly smaller $(P<0.05)$ than the average number of mismatches (3.4) among the same number of re-sampled bats from the Balkan (the value corresponding to $5 \%$ thresh- 
Table 1 Genetic organization of colonies and swarming sites of the Bechstein's bat for seven nucDNA and two mtDNA microsatellites. We show the medians (and ranges) of the numbers of sampled bats, and the means ( \pm SD) of three indices of genetic diversity, and $F_{\text {IS }}$ values for populations located either in the 'Balkan' or in the rest of 'Europe'. In addition, mean $( \pm \mathrm{SD}) F_{\mathrm{ST}}$ values among colonies and among swarming sites are given (see text for details)

\begin{tabular}{lclllrrr}
\hline & No. of bats & \multicolumn{1}{l}{$H_{\mathrm{S}}$} & \multicolumn{1}{l}{$A_{\mathrm{R}}$} & $h$ & $F_{\mathrm{IS}}$ & $F_{\mathrm{ST}}(\mathrm{nucDNA})$ & $F_{\mathrm{ST}}(\mathrm{mtDNA})$ \\
\hline 'Europe' & & & & & & \\
Colonies $(n=46)$ & $15.5(4-93)$ & $0.82 \pm 0.02$ & $4.08 \pm 0.15$ & $0.31 \pm 0.25$ & $-0.02 \pm 0.05$ & $0.03 \pm 0.02$ & $0.62 \pm 0.23$ \\
$\begin{array}{l}\text { Swarming sites }(n=9) \\
\text { 'Balkan' }\end{array}$ & $6.0(3-106)$ & $0.86 \pm 0.03$ & $4.33 \pm 0.25$ & $0.82 \pm 0.12$ & $0.01 \pm 0.03$ & $0.01 \pm 0.02$ & $0.13 \pm 0.10$ \\
Colonies $(n=4)$ & & & & & & \\
Swarming sites $(n=11)$ & $6.5(6-20)$ & $0.86 \pm 0.01$ & $4.39 \pm 0.20$ & $0.59 \pm 0.11$ & $0.02 \pm 0.09$ & $0.03 \pm 0.02$ & $0.40 \pm 0.06$ \\
& $6.0(3-48)$ & $0.88 \pm 0.02$ & $4.53 \pm 0.18$ & $0.90 \pm 0.10$ & $0.00 \pm 0.05$ & $-0.01 \pm 0.01$ & $0.05 \pm 0.09$ \\
\hline
\end{tabular}

old is 1.0). Using the same two subsets of bats from the Balkan as for ND1 always resulted in significant results for HV2 (data not shown).

\section{Genetic diversity and structure of breeding colonies and swarming sites}

We detected no Hardy-Weinberg disequilibrium in the nuclear data set. $F_{\text {IS }}$ values at swarming sites and colonies were low (Table 1, Appendix) and not significantly different from zero after correcting for multiple tests. Gene diversities $\left(H_{\mathrm{S}}\right)$ for the seven autosomal loci ranged from $0.74 \pm 0.06-0.89 \pm 0.05$ in the 50 colonies, and from $0.78 \pm 0.06-0.93 \pm 0.06$ in the 20 swarming sites. Randomization tests revealed that swarming sites had significantly higher genetic diversities than colonies $\left(P<0.0005\right.$ for $H_{S^{\prime}}$ $A_{\mathrm{R}^{\prime}}$ and $h$; Table 1$)$. However, when we split the sample according to the location of the populations with respect to the glacial refugium, this difference was only significant for populations outside the Balkan (Balkan: $n_{1}=4$ colonies, $n_{2}=11$ swarming sites: $H_{\mathrm{S}}: P=0.75 ; A_{\mathrm{R}}: P=0.35 ; h$ : $P=0.32$; rest of Europe: $n_{1}=46$ colonies, $n_{2}=9$ swarming sites: $H_{\mathrm{S}}: P<0.02, A_{\mathrm{R}}: P<0.01, h: P<0.0005$; Table 1$)$.

Overall, the 70 populations were about 25 times more differentiated for mtDNA than for nucDNA ( $F_{\mathrm{ST}}: 0.51 \mathrm{vs}$. 0.02 ), and the 50 colonies were significantly stronger differentiated than the 20 swarming sites (mtDNA: 0.66 vs. $0.12, P<0.001$; nucDNA: 0.02 vs. $0.01, P<0.005$ ). However, we found no significant difference in the differentiation of populations $\left(F_{\mathrm{ST}}\right)$ inside and outside the Balkan refugium (nucDNA: swarming sites: $P=0.43$; colonies: $P=0.92$; mtDNA: swarming sites: $P=0.87$; colonies: $P=0.58$; Table 1). Moreover, colonies inside and outside of the Balkan had the same mean relatedness among their members $(r=0.04)$ but higher $r$ values than bats at swarming sites (Balkan: $r=0.00, P=0.07$; rest of Europe: $r=0.01, P=0.03$ ).

Genetic diversity at the nuclear and mitochondrial microsatellites decreased with increasing latitude. However, this pattern was only significant for swarming sites
(Spearman rank correlation: swarming sites: $H_{\mathrm{S}}: r_{\mathrm{S}}=-0.56$, $P=0.01 ; A_{\mathrm{R}}: r_{\mathrm{S}}=-0.58, P<0.01 ; h: r_{\mathrm{S}}=-0.45, P<0.05$; colonies: $H_{\mathrm{S}}: r_{\mathrm{S}}=-0.15, P=0.32 ; A_{\mathrm{R}}: r_{\mathrm{S}}=-0.17, P=0.24 ; h$ : $r_{\mathrm{S}}=-0.10, P=0.50$ ). For nucDNA, populations from the Balkan were considerably more diverse than the populations from the rest of Europe (randomization test: swarming sites: $H_{S}: P=0.05 ; A_{\mathrm{R}}: P=0.06$; colonies: $H_{\mathrm{S}}: P<0.005$; $A_{\mathrm{R}}: P=0.01$; Table 1). For mtDNA, this difference was not significant (swarming sites: $h: P=0.85$; colonies: $h: P=0.50$; Table 1).

\section{Test for recent bottlenecks}

We detected no evidence for recent bottlenecks in the sampled populations. None of the seven swarming sites and 37 colonies with more than 10 samples showed significant heterozygote excess ( $P$ was always $>0.14$ ). Moreover, the five swarming sites and nine colonies with more than 30 samples all exhibited an L-shaped allelic distribution.

\section{Demography at colonies and swarming sites}

All sampled colonies in Central Europe and the Balkan comprised only adult females and their offspring. At 10 of the 19 swarming sites for which we have sex-ratio data, both sexes occurred (at nine swarming sites, only males were captured). Sex ratios among swarming bats were similarly male biased in Central and Western Europe compared to the Balkan (Mann-Whitney $U$-test: $82 \pm 14 \%$ vs. $91 \pm 13 \%$ males; $U=27, n_{1}=8, n_{2}=11 ; P=0.14$ ).

\section{Discussion}

Several recent studies have dealt with the phylogeography of European bats (Petit et al. 1999; Ruedi \& Castella 2003; Rossiter et al. 2007). However, our study is the first that uses phylogeographical data to assess whether there is variation in the social organization and the mating system of a bat species across its range. This kind of information is required 
to understand the evolution of social systems in bats and to design efficient conservation plans (Lott 1991; Burland \& Worthington Wilmer 2001).

\section{Glacial refugia and re-colonization of Central Europe}

Glacial refugia often harbour higher genetic diversities than areas that have been re-colonized after the ice retreaded (Hewitt 1999). Our mismatch analyses of the fastevolving HV2 region and the more conserved ND1 gene both showed that the Balkan harbours greater haplotype diversity than the rest of Europe. On the contrary, bats from the Italian and Iberian peninsulas carried HV2 and ND1 haplotypes that are identical or very similar to the Central European haplotypes. Due to the scarcity of the Bechstein's bat in Iberia and Italy (Baagøe 2001), our sample sizes in these potential refugia (Taberlet et al. 1998; Hewitt 1999) are small and we cannot rule out that more divergent haplotypes remained unsampled. Our bootstrap analyses, however, revealed that at least for HV2, our sample size is sufficient to confirm significantly less diverse haplotypes in Iberia compared to the Balkan. Low diversity in Iberian Bechstein's bats has also been reported for the mitochondrial cytochrome $b$ gene (Ibanez et al. 2006). Finally, only populations occurring outside the Balkan showed clear signs of postglacial population expansion (Fig. 4). We conclude that the Balkan was the main, and probably only, glacial refugium of the Bechstein's bat in Europe.

High diversities of nuclear and mitochondrial microsatellites in colonies and at swarming sites in Bulgaria and the European part of Turkey are consistent with a glacial refugium in the Balkan. Even though the negative correlation between genetic diversity and latitude was only significant for swarming sites, our randomization tests showed that Bulgarian colonies are significantly more diverse than Central European colonies at the level of nucDNA. The absence of genetic signals from recent bottlenecks suggests that anthropogenic loss of deciduous forest is not the cause of the lower genetic diversities outside the Balkan.

Currently, Myotis bechsteinii is the only bat species that shows lower diversity of both mtDNA and nucDNA at higher latitudes. A negative correlation between nucDNA diversity and latitude was also found in Rhinolophus ferrumequinum (Rossiter et al. 2007). In contrast, no such correlation occurred in Nyctalus noctula (Petit et al. 1999) and in Myotis myotis, only mtDNA diversity decreased with higher latitude (Ruedi \& Castella 2003). Lower genetic diversities in re-colonized areas occur mostly in species, such as M. bechsteinii, that have low dispersal abilities and specific habitat requirements (Schmitt 2007). In such species, the genetic consequences of founder effects during the re-colonization period (i.e. low genetic diversity) are more likely to persist because the lack of long-distance gene flow from glacial refugia prevents the homogenizing of genetic diversities.

The inferred postglacial re-colonization of Central Europe from the Balkan in M. bechsteinii resembles more the situation described for N. noctula (Petit et al. 1999) than for M. myotis (Ruedi \& Castella 2003). This is interesting as $N$. noctula belongs to a different genus than M. bechsteinii, is migratory, and shorter lived (Dietz et al. 2007). Nevertheless, both species largely depend on tree cavities for breeding. Myotis myotis, on the contrary, belongs to the same genus as $M$. bechsteinii and is similarly long-lived, but uses caves and attics for breeding (Dietz et al. 2007). Breeding habitat thus explains postglacial re-colonization routes better than phylogenetic relationship, dispersal ability, or generation time. In Central Europe, beech forest Fagus sylvatica often dominates the breeding habitat of $M$. bechsteinii (Baagøe 2001). Association with beech forests that survived the ice ages in Southeast Europe (Magri et al. 2006) could explain why the Balkan was the main glacial refugium in the two forest-living bat species, M. bechsteinii and N. noctula (compare Petit et al. 1999).

ND1 sequence divergences of $0.2-1.2 \%$ among Bechstein's bats in Europe suggest that the separation between the most divergent European haplotypes predates the last glacial maximum (18 000 years ago), applying a typical mammalian ND1 divergence rate of $0.5-2 \%$ per million years (Petit et al. 1999). The same situation was observed in N. noctula (Petit et al. 1999) and other European taxa (Schmitt 2007). Moreover, this finding is confirmed by 0.4$4.9 \%$ divergences in HV2 in the European Bechstein's bat populations, applying a divergence rate of $20 \%$ per million year as estimated for N. noctula (Petit et al. 1999). Finally, divergences of 5.2-6.8\% between the European and the Anatolian/Caucasian ND1 haplotypes suggest that populations in Europe were separated from those in Anatolia/ Caucasus much earlier. In fact, the observed divergences fall into the range found for different subspecies in the genus Myotis (Ruedi \& Mayer 2001), and may even indicate the presence of cryptic species (Mayer et al. 2007).

\section{Social system within and outside of the glacial refugium}

Social systems are characterized by the social organization, mating system, and social interactions of a species (Kappeler \& van Schaik 2002). Social organizations (group composition) and mating systems can be studied using a combination of demographic and genetic data. During our tissue sampling in the breeding colonies of the Bechstein's bat, we found no adult males in the same roosts as the females. This is in agreement with a long-term study on a German breeding colony (Kerth \& Morf 2004), where adult males and females only exceptionally roosted together. In contrast, we observed a strong male bias among swarming 
bats, irrespective of the location of a swarming site. Again, this finding is in agreement with previous observations from Germany (Kerth et al. 2003). Our demographic data, hence, suggest that the social organization of the Bechstein's bat does not fundamentally differ between the Balkan and Central Europe.

Our genetic analyses confirm these results and provide additional information about the mating system of Bechstein's bats. Both inside and outside of the Balkan area, higher genetic diversities occurred at swarming sites than in breeding colonies. Moreover, populations were much more strongly differentiated for mtDNA than for nucDNA, even if we consider the four times larger effective population size $\left(N_{e}\right)$ of nucDNA. In addition, Central European and Balkan populations both showed more differentiation between colonies than between swarming sites, and higher levels of relatedness in colonies than among swarming bats. Finally, $F_{\text {IS }}$ values were always low and not significantly different from zero. We conclude that Balkan populations, like Central European populations (Kerth et al. 2002, 2003), are shaped by strong female natal philopatry, complete male natal dispersal, and outbreeding that takes place at swarming sites.

Our data are in agreement with Bechstein's bats having a social system that is independent from the postglacial history and location of the populations. This is interesting because flexible social systems are common in other animals (Lott 1991; Ross \& Keller 1995). The 'socio-ecological' model explains intraspecific variation in social systems with variation in the local environment (Lott 1991; Ross \& Keller 1995; Kappeler \& van Schaik 2002). However, apart from social insects (Ross \& Keller 1995), little is known about the influence of the geographical location and the population history on the intraspecific social system variation. Anecdotic data suggest that in several bat species, the proportion of males in breeding colonies varies between different parts of Europe (Dietz et al. 2007). More detailed data for brown long-eared bats (Plecotus auritus) show that male philopatry increases with latitude (Entwistle et al. 2000).

According to the socio-ecological model, the lack of variation in the social organization and mating system of the Bechstein's bat should be an adaptation to a stable environment. Bechstein's bats associate with mature deciduous forest all over their range (Baagøe 2001). This suggests that the species is very specific in its habitat requirements. Within the preferred habitat type, the benefits of female philopatry and sociality are probably largely independent from local habitat conditions since females seem to profit from communal breeding in a familiar social environment (Kerth et al. 2000). This scenario may apply to other European bat species as well, since in all of them, the females are social and philopatric (Burland \& Worthington Wilmer 2001). Uniform natal dispersal in male Bechstein's bats is more difficult to explain. Female philopatry combined with inbreeding avoidance selects for male dispersal (Lawson Handley \& Perrin 2007). However, since Bechstein's bats mate at swarming sites (Kerth \& Morf 2004), females could outbreed even if both sexes were philopatric to their natal colonies. For comparison, in Scotland, male P. auritus roost in their natal colonies but mate elsewhere (Burland \& Worthington Wilmer 2001). The positive correlation between latitude and the degree of male philopatry in $P$. auritus has been explained with energetic benefits of communal roosting in cold areas (Entwistle et al. 2000). Our data suggest that in $M$. bechsteinii the benefits of the extremely sex-biased dispersal and the strict female sociality are independent of local conditions that vary with latitude, such as climate.

Phylogenetic inertia could also explain the absence of social system variation (Lott 1991). This explanation, however, is unlikely to fully explain the observed lack of variation in the social system of the Bechstein's bat. The existence of intra- and interspecific social system variation in other European bat species (Entwistle et al. 2000; Safi \& Kerth 2007) suggests that bat social systems are not totally constrained by phylogeny.

\section{Implications for conservation}

Our results have several direct implications for the conservation of the endangered Bechstein's bat. First, the large phylogenetic divergence between the Bechstein's bat populations in Europe and those in Anatolia and the Caucasus show that the two types of populations must be managed as different evolutionary units (Palsbøll et al. 2007). Second, higher genetic diversities in the Balkan compared to the rest of Europe suggest that populations in Bulgaria, Greece, and the European part of Turkey should be protected with particular care since they carry a substantial part of the genetic variation (compare Schmitt 2007). Finally, our finding that the social system of the Bechstein's bat does not fundamentally differ between Central and Southeast Europe means that the current management guidelines, which have been mostly based on data from Central European populations (e.g. Kerth et al. 2000, 2003), should also apply to populations in other parts of Europe. Effective conservation of Bechstein's bats implies the strict protection of breeding colonies, because they are demographically independent units (Kerth et al. 2000). Swarming sites have to be protected as well since they assure the flow of nuclear genes between the colonies (Kerth et al. 2003).

The information that Bechstein's bats have a stable social system throughout their European range is good and bad news at the same time. It is good news because it allows the design of management plans and habitat protection legislatives such as the European FFH-directive (Dietz et al. 
2007), which are applicable throughout Europe. It is bad news because it suggests that Bechstein's bats are highly susceptible to environmental changes that disrupt their social system, for example the loss of underground sites used for mating or the cutting and fragmentation of mature deciduous forest used for breeding.

\section{Acknowledgements}

We thank J. Garbely for the laboratory work, F. Mayer, J. Yearsley and three anonymous referees for helpful comments on the manuscript. We are grateful to the following people for providing access to samples: P. Agnelli, M. Baratavo, E. Barrat, A-T. Bashta, P. Benda, C. Dietz, A. Fayard, J. Flanders, U. Hoffmeister, C. Ibanez, J. Juste, A. Kiefer, G. Knipfer, R. Leitl, F. Mayer, M. Melber, Z. Nagy, J-F. Noblet, B. Özkan, E. Petit, H. Rebelo, K. Reckardt, M. Ruedi, G. Schlapp, J. Tiago Marques, and C. Trappmann. Sampling of Bechstein's bats was carried out under license from the responsible nature conservancy departments. The national science foundations of Germany (DFG, KE 746, 2-1), Switzerland (SNF, 3159556.99, 7BUPJ062292), and Russia (RFBR, 07-04-01215) as well as the National Geographic Society (8001-06) supported the study. We dedicate this paper to our colleague Tihomir Stoyanov, who recently died while following his passion of mountain climbing.

\section{References}

Baagøe HJ (2001) Myotis bechsteinii (Kuhl, 1818) Bechsteinfledermaus. In: Handbuch der Säugetiere Europas, Band 4/I (eds Niethammer J, Krapp F), pp. 443-471. Aula Verlag, Weibelsheim, Germany.

Burland TM, Worthington Wilmer J (2001) Seeing in the dark: molecular approaches to the study of bat populations. Biological Reviews, 76, 389-409.

Chen S-F, Rossiter SJ, Faulkes CG, Jones G (2006) Population genetic structure and demographic history of the endemic Formosan lesser horseshoe bat (Rhinolophus monoceros). Molecular Ecology, 15, 1643-1656.

Cornuet JM, Luikart G (1996) Description and power analysis of two tests for detecting recent population bottlenecks from allele frequency data. Genetics, 144, 2001-2014.

Dietz C, Helversen O, Nill D (2007) Handbuch der Fledermäuse Europas und Nordwestafrikas. Kosmos Verlag (Franckh-Kosmos, Stuttgart, Germany.

Ditchfield AD (2000) The comparative phylogeography of Neotropical mammals: patterns of intraspecific mitochondrial DNA variation among bats contrasted to nonvolant small mammals. Molecular Ecology, 9, 1307-1318.

Edwards SV (1993) Long-distance gene flow in a cooperative breeder detected in genealogies of mitochondrial-DNA sequences. Proceedings of the Royal Society B: Biological Sciences, 252, 177-185.

Entwistle AC, Racey PA, Speakman JR (2000) Social and population structure of a gleaning bat, Plecotus auritus. Journal of Zoology, 225, 11-17.

Fu Y-X (1997) Statistical test of neutrality of mutations against population growth, hitchhiking, and background selection. Genetics, 147, 915-925.

Goudet J (1995) FSTAT (version 1.2): a computer program to calculate F-statistics. Journal of Heredity, 86, 485-486.
Goudet J, Raymond M, de Meeus T, Rousset F (1996) Testing differentiation in diploid populations. Genetics, 144, 1933-1940.

Guindon S, Gascuel O (2003) A simple, fast, and accurate algorithm to estimate large phylogenies by maximum likelihood. Systematic Biology, 52, 696-704.

Hasegawa M, Kishino H, Yano TA (1985) Dating of the human ape splitting by a molecular clock of mitochondrial-DNA. Journal of Molecular Evolution, 22, 160-174.

Hewitt GM (1996) Some genetic consequences of ice ages, and their role in divergence and speciation. Biological Journal of the Linnean Society, 58, 247-276.

Hewitt GM (1999) Post-glacial re-colonization of European biota. Biological Journal of the Linnean Society, 68, 87-112.

Huelsenbeck JP, Ronquist F, Nielsen R, Bollback JP (2001) Evolution - Bayesian inference of phylogeny and its impact on evolutionary biology. Science, 294, 2310-2314.

Ibanez C, Garcia-Mudarra JL, Ruedi M, Stadelmann B, Juste J (2006) The Iberian contribution to cryptic diversity in European bats. Acta Chiropterologica, 8, 277-297.

Kappeler PM, van Schaik CP (2002) Evolution of primate social systems. International Journal of Primatology, 23, 707-740.

Kerth G, Morf L (2004) Behavioural and genetic data suggest that Bechstein's bats predominantely mate outside the breeding habitat. Ethology, 110, 987-999.

Kerth G, Petit E (2005) Colonization and dispersal in a social species, the Bechstein's bat (Myotis bechsteinii). Molecular Ecology, 14, 3943-3950.

Kerth G, Mayer F, König B (2000) Mitochondrial DNA (mtDNA) reveals that female Bechstein's bats live in closed societies. Molecular Ecology, 9, 793-800.

Kerth G, Mayer F, Petit E (2002) Extreme sex-biased dispersal in the communally breeding, non-migratory Bechstein's bats (Myotis bechsteinii). Molecular Ecology, 11, 1491-1498.

Kerth G, Kiefer A, Trappmann C, Weishaar M (2003) High gene diversity at swarming sites suggests hot spots for gene flow in the endangered Bechstein's bat. Conservation Genetics, 4, 491499.

Lawson Handley JL, Perrin N (2007) Advances in our understanding of mammalian sex-biased dispersal. Molecular Ecology, 16, 1559-1578.

Lott DF (1991) Intraspecific Variation in the Social Systems of Wild Vertebrates. Cambridge University Press, New York.

Luikart G, Allendorf FW, Cornuet JM, Sherwin WB (1998) Distortion of allele frequency distributions provides a test for recent population bottlenecks. Journal of Heredity, 89, 238-247.

Magri D, Vendramin GG, Comps B et al. (2006) A new scenario for the Quaternary history of European beech populations: palaeobotanical evidence and genetic consequences. New Phytologist, 171, 199-221.

Mayer F, Dietz C, Kiefer A (2007) Molecular species identification boosts bat diversity. Frontiers in Zoology, 4, 4 doi: 10.1186/17429994-4-4.

Mikusinski G, Angelstam P (1998) Economic geography, forest distribution, and woodpecker diversity in central Europe. Conservation Biology, 12, 200-208.

Palsbøll PJ, Berube M, Allendorf FW (2007) Identification of management units using population genetic data. Trends in Ecology E Evolution, 22, 11-16.

Petit E, Excoffier L, Mayer F (1999) No evidence of bottleneck in the postglacial recolonization of Europe by the noctule bat (Nyctalus noctula). Evolution, 53, 1247-1258. 
Piry S, Luikart G, Cornuet JM (1999) вотTLENECK: a computer program for detecting recent reductions in the effective population size using allele frequency data. Journal of Heredity, 90, 502-503.

Posada D, Crandall KA (1998) Modeltest: testing the model of DNA substitution. Bioinformatics, 14, 817-818.

R Development Core Team (2006) R: a Language and Environment for Statistical Computing. R Foundation for Statistical Computing, Vienna, Austria.

Rivers NM, Butlin RK, Altringham JD (2005) Genetic population structure of Natterer's bats explained by mating at swarming sites and philopatry. Molecular Ecology, 14, 4299-4312.

Ross KG, Keller L (1995) Ecology and evolution of socialorganization: insights from fire ants and other highly eusocial insects. Annual Review of Ecology and Systematics, 26, 631-656.

Rossiter RJ, Benda P, Dietz C, Zhang S, Jones G (2007) Rangewide phylogeography in the greater horseshoe bat inferred from microsatellites: implications for population history, taxonomy and conservation. Molecular Ecology, online first, doi: 10.1111/ j.1365-294X.2007.03546.x.

Rudolph B-U, Kerth G, Schlapp G, Wolz I (2004) Bechsteinfledermaus Myotis bechsteinii (Kuhl, 1817). In: Fledermaüse in Bayern (eds Meschede A, Rudolph B-U), pp. 188-202. Ulmer Verlag, Stuttgart, Germany.

Ruedi M, Castella V (2003) Genetic consequences of the ice ages on nurseries of the bat Myotis myotis: a mitochondrial and nuclear survey. Molecular Ecology, 12, 1527-1540.

Ruedi M, Mayer F (2001) Molecular systematics of bats of the genus Myotis (Vespertilionidae) suggests deterministic ecomorphological convergences. Molecular Phylogenetics and Evolution, 21, 436-448.

Russell AL, Medellín RA, McCracken GF (2005) Genetic variation and migration in the Mexican free-tailed bat (Tadarida brasiliensis mexicana). Molecular Ecology, 14, 2207-2222.

Safi K, Kerth G (2007) Comparative analyses suggest that information transfer promoted sociality in male bats. American Naturalist, 170, 465-472.

Schmitt T (2007) Molecular biogeography of Europe: Pleistocene cycles and postglacial trends. Frontiers in Zoology, 4, 11. doi: 10.1186/1742-9994-4-11.

Schneider S, Excoffier L (1999) Estimation of past demographic parameters from the distribution of pairwise differences when the mutation rates very among sites: application to human mitochondrial DNA. Genetics, 152, 1079-1089.

Schneider S, Roessli D, Excoffier L (2000) ARLEQUIN, Version 2001. A Software for Population Genetic Data Analysis. Genetics and Biometry Laboratory, Department of Anthropology, University of Geneva, Switzerland.

Swofford DL (2002) Phylogenetic Analysis Using Parsimony. Sinauer \& Associates, Sunderland, Massachusetts.

Taberlet P, Fumagalli L, Wust-Saucy A-G, Cosson J-F (1998) Comparative phylogeography and post-glacial colonization routes in Europe. Molecular Ecology, 7, 453-464.

Tajima F (1989) Statistical method for testing the neutral mutation hypothesis by DNA polymorphism. Genetics, 123, 585-595.

Veith M, Beer N, Kiefer A, Johannesen J, Seitz A (2004) The role of swarming sites for maintaining gene flow in the brown longeared bat (Plecotus auritus). Heredity, 93, 342-349.

Weir BS, Cockerham CC (1984) Estimating F-statistics for the analysis of population structure. Evolution, 38, 1358-1370.

Weynand SE, van den Busche RA (2007) Phylogeographic structuring and volant mammals: the case of the pallid bat (Anthrozous pallidus). Journal of Biogeography, 34, 1233-1245.

Wilkinson GS, Fleming TH (1996) Migration and evolution of lesser long-nosed bats Leptonycteris curasoae, inferred from mitochondrial DNA. Molecular Ecology, 5, 329-339.

Wilkinson GS, South JM (2002) Life history, ecology and longevity in bats. Aging Cell, 1, 124-131.

Worthington Wilmer J, Hall L, Barratt E, Moritz C (1999) Genetic structure and male-mediated gene flow in the ghost bat (Macroderma gigas). Evolution, 53, 1582-1591.

G.K., B.P., A.C., D.A., M.W., S.G., and N.B. all share an interest in bat biology. G.K.'s research focuses on the behavioural ecology and sociogenetics of bats. B.P., A.C., D.A., M.W., and S.G. are mostly interested in the ecology and conservation of bats, and N.B. in the phylogeography of bats and their parasites. B.K.'s research focuses on the behavioural ecology of mammals and the research of J.J. and N.P. deals, among other aspects, with the causes and consequences of dispersal. 


\section{Appendix}

Location of the 20 swarming sites and the 50 colonies used in our analyses. We give the name of each site (names in Italic indicate that a site is located inside the inferred Balkan refugium), numbers of sampled bats, country of origin, the latitude in degrees, three indices of genetic diversity, and $F_{\mathrm{IS}}$ values

Colonies

\begin{tabular}{|c|c|c|c|c|c|c|c|}
\hline Site & No. of bats & Country & Latitude & $h$ & $H_{\mathrm{S}}$ & $A_{\mathrm{R}}$ & $F_{\mathrm{IS}}$ \\
\hline BAU & 62 & Germany & 51.97 & 0.91 & 0.85 & 4.32 & 0.01 \\
\hline ENGD & 3 & England & 50.35 & 1.00 & 0.85 & 4.00 & -0.01 \\
\hline MAY & 3 & Germany & 50.33 & 0.67 & 0.83 & 4.14 & -0.03 \\
\hline BKSS & 3 & Germany & 49.54 & 0.67 & 0.93 & 4.86 & 0.03 \\
\hline SSP & 6 & Germany & 49.53 & 0.73 & 0.85 & 4.24 & 0.08 \\
\hline $\mathrm{BOH}$ & 106 & Germany & 49.47 & 0.78 & 0.84 & 4.20 & 0.00 \\
\hline $\mathrm{THO}$ & 67 & Germany & 49.45 & 0.82 & 0.84 & 4.22 & 0.01 \\
\hline $\mathrm{RMC}$ & 5 & Romania & 46.13 & 0.90 & 0.88 & 4.52 & -0.01 \\
\hline SNS & 31 & Serbia & 45.15 & 0.92 & 0.87 & 4.46 & 0.03 \\
\hline$B L O$ & 4 & Bulgaria & 43.02 & 0.83 & 0.88 & 4.49 & 0.03 \\
\hline BIS & 48 & Bulgaria & 43.00 & 0.83 & 0.86 & 4.41 & -0.02 \\
\hline$B C G$ & 3 & Bulgaria & 42.49 & 0.67 & 0.86 & 4.43 & -0.06 \\
\hline$B V D$ & 3 & Bulgaria & 42.44 & 1.00 & 0.86 & 4.43 & -0.06 \\
\hline$B S M$ & 17 & Bulgaria & 42.09 & 0.93 & 0.88 & 4.57 & 0.04 \\
\hline$B S B$ & 12 & Bulgaria & 42.00 & 0.88 & 0.87 & 4.37 & 0.01 \\
\hline$B S K$ & 8 & Bulgaria & 42.00 & 0.96 & 0.88 & 4.55 & 0.05 \\
\hline TSS & 6 & Turkey & 41.50 & 0.93 & 0.89 & 4.61 & 0.09 \\
\hline BPI1 & 3 & Bulgaria & 41.44 & 1.00 & 0.89 & 4.57 & 0.04 \\
\hline BPI2 & 3 & Bulgaria & 41.42 & 1.00 & 0.90 & 5.00 & -0.05 \\
\hline$B Y A$ & 7 & Bulgaria & 41.37 & 0.86 & 0.86 & 4.40 & -0.05 \\
\hline
\end{tabular}

Colonies

\begin{tabular}{|c|c|c|c|c|c|c|c|}
\hline $\mathrm{BF}$ & 14 & Germany & 52.78 & 0.78 & 0.82 & 4.00 & 0.03 \\
\hline GO & 12 & Germany & 52.40 & 0.17 & 0.82 & 4.03 & 0.05 \\
\hline DU & 20 & Germany & 50.16 & 0.19 & 0.83 & 4.14 & -0.04 \\
\hline OK & 20 & Germany & 50.05 & 0.44 & 0.83 & 4.19 & -0.05 \\
\hline SF & 16 & Germany & 50.04 & 0.44 & 0.81 & 4.09 & -0.04 \\
\hline GI & 27 & Germany & 50.01 & 0.36 & 0.83 & 4.17 & -0.06 \\
\hline BA1 & 14 & Germany & 50.00 & 0.00 & 0.81 & 3.90 & 0.04 \\
\hline BA2 & 9 & Germany & 50.00 & 0.00 & 0.85 & 4.19 & -0.01 \\
\hline GS2 & 22 & Germany & 49.95 & 0.52 & 0.82 & 4.09 & -0.01 \\
\hline GS3 & 17 & Germany & 49.92 & 0.00 & 0.78 & 3.87 & -0.03 \\
\hline GS1 & 93 & Germany & 49.91 & 0.04 & 0.82 & 4.07 & -0.01 \\
\hline ES & 10 & Germany & 49.90 & 0.00 & 0.81 & 3.97 & -0.02 \\
\hline BW & 19 & Germany & 49.90 & 0.00 & 0.87 & 4.38 & 0.01 \\
\hline ARG & 16 & Germany & 49.88 & 0.46 & 0.79 & 3.88 & -0.03 \\
\hline $\mathrm{RB}$ & 14 & Germany & 49.87 & 0.58 & 0.85 & 4.30 & -0.10 \\
\hline EI & 10 & Germany & 49.86 & 0.53 & 0.83 & 4.17 & -0.04 \\
\hline $\mathrm{HB}$ & 57 & Germany & 49.79 & 0.70 & 0.83 & 4.12 & -0.03 \\
\hline $\mathrm{SH}$ & 4 & Germany & 49.77 & 0.50 & 0.85 & 4.05 & 0.11 \\
\hline WBR & 10 & Germany & 49.76 & 0.53 & 0.81 & 4.12 & 0.07 \\
\hline WF & 15 & Germany & 49.76 & 0.53 & 0.81 & 3.90 & -0.04 \\
\hline KAL & 16 & Germany & 49.75 & 0.13 & 0.83 & 4.04 & -0.04 \\
\hline GB2 & 70 & Germany & 49.74 & 0.36 & 0.83 & 4.16 & 0.00 \\
\hline RT & 18 & Germany & 49.74 & 0.52 & 0.81 & 4.01 & -0.03 \\
\hline IB1 & 20 & Germany & 49.74 & 0.34 & 0.81 & 3.98 & -0.05 \\
\hline BS & 30 & Germany & 49.73 & 0.56 & 0.85 & 4.29 & 0.01 \\
\hline IB2 & 17 & Germany & 49.72 & 0.32 & 0.84 & 4.19 & -0.03 \\
\hline IB3 & 16 & Germany & 49.72 & 0.23 & 0.83 & 4.20 & -0.02 \\
\hline UH & 42 & Germany & 49.72 & 0.05 & 0.84 & 4.14 & -0.01 \\
\hline GB1 & 39 & Germany & 49.71 & 0.30 & 0.84 & 4.19 & 0.03 \\
\hline SB & 34 & Germany & 49.71 & 0.00 & 0.79 & 3.90 & -0.01 \\
\hline $\mathrm{RD}$ & 7 & Germany & 49.59 & 0.81 & 0.76 & 3.81 & -0.13 \\
\hline GA & 5 & Germany & 49.59 & 0.00 & 0.79 & 3.72 & -0.13 \\
\hline
\end{tabular}


14 G. KERTH ET AL.

Appendix Continued

\begin{tabular}{|c|c|c|c|c|c|c|c|}
\hline \multicolumn{8}{|c|}{ Colonies } \\
\hline Site & No. of bats & Country & Latitude & $h$ & $H_{\mathrm{S}}$ & $A_{\mathrm{R}}$ & $F_{\mathrm{IS}}$ \\
\hline BI & 9 & Germany & 49.58 & 0.00 & 0.85 & 4.22 & 0.01 \\
\hline AL2 & 8 & Germany & 49.57 & 0.46 & 0.82 & 4.08 & 0.00 \\
\hline $\mathrm{RH}$ & 17 & Germany & 49.57 & 0.00 & 0.84 & 4.22 & -0.02 \\
\hline SD & 62 & Germany & 49.57 & 0.28 & 0.84 & 4.26 & -0.01 \\
\hline AL1 & 7 & Germany & 49.56 & 0.52 & 0.79 & 3.94 & -0.03 \\
\hline ST & 11 & Germany & 49.56 & 0.55 & 0.86 & 4.29 & 0.01 \\
\hline BKS & 6 & Germany & 49.55 & 0.00 & 0.78 & 3.92 & -0.04 \\
\hline NW & 4 & Germany & 49.55 & 0.50 & 0.82 & 3.92 & 0.08 \\
\hline $\mathrm{JB}$ & 12 & Germany & 49.46 & 0.17 & 0.81 & 4.08 & -0.01 \\
\hline HW & 6 & Germany & 49.35 & 0.60 & 0.81 & 4.05 & -0.03 \\
\hline $\mathrm{KR}$ & 10 & Germany & 49.27 & 0.36 & 0.80 & 4.04 & -0.06 \\
\hline $\mathrm{HH}$ & 11 & Germany & 49.25 & 0.00 & 0.83 & 4.17 & 0.03 \\
\hline SÜ & 6 & Germany & 49.18 & 0.00 & 0.86 & 4.42 & -0.05 \\
\hline $\mathrm{BZ}$ & 30 & Switzerland & 47.29 & 0.41 & 0.80 & 3.83 & -0.03 \\
\hline MS & 20 & Bulgaria & 42.60 & 0.66 & 0.86 & 4.40 & 0.01 \\
\hline$R P 2$ & 11 & Bulgaria & 42.19 & 0.69 & 0.87 & 4.47 & 0.15 \\
\hline$R P 3$ & 8 & Bulgaria & 42.19 & 0.46 & 0.87 & 4.59 & -0.05 \\
\hline$R P 1$ & 6 & Bulgaria & 42.18 & 0.53 & 0.85 & 4.11 & -0.01 \\
\hline
\end{tabular}

